\title{
Examining the Relationship between Organizational Identification and Learning Organization Dimensions: A Study of a U.S. Franchise
}

\author{
Simon Reese ${ }^{1, *}$ \\ ${ }^{1}$ Graduate School of Education \& Human Development, The George Washington University, Washington D.C., USA \\ *Correspondence: 21270 Smokehouse Ct, Ashburn, VA 20147, USA. Tel: 1-703-597-2160. E-mail: \\ srreese@gwu.edu
}

Received: December 16, 2013

Accepted: January 7, $2014 \quad$ Online Published: January 14, 2014

doi:10.5430/mos.v1n1p7

URL: http://dx.doi.org/10.5430/mos.v1n1p7

\begin{abstract}
Organizational identification and learning organization dimensions both have been shown to create positive organizational impacts. Although both concepts are closely related in their origins from social context, limited studies exist to uncover if these concepts are interrelated and none appear in the context of a franchise organization.

This study explored the relationship between the perception of organizational identification and perceptions of learning organization dimensions in a medium-sized, U.S.-based franchise organization with 81 franchisees.

The study used a quantitative research design and a 35-item survey instrument. The survey instrument consisted of three sections: (a) demographic questions, (b) organizational identification questions from Edwards and Peccei's (2007) instrument, and (c) dimension of the learning organization questions from Watkins and Marsick's (2003) dimension of the learning organization questionnaire.

A total of 51 respondents completed the survey instrument. Descriptive statistics and correlations using Pearson product-moment correlation coefficients were analyzed.

The findings suggested that the descriptive statistics from a franchise network were no different from those from previous studies in numerous different business formats, which indicated that the relationships within the franchise being studied were similar to those within an integrated organization. Furthermore, the study concluded that within this franchise there was a correlation between organizational identification and learning organization dimension, which leads to new areas for further theoretical exploration and practical application. Implications include new methods to manage a franchise network and further considerations in utilizing both organizational identification and learning organization mechanisms simultaneously to create the greatest positive impact of both.
\end{abstract}

Keywords: organizational learning, learning organization, organizational identification, franchise, inter-business relationship, inter-organizational relationship

\section{Introduction}

\subsection{Introduce the Problem}

The purpose of this exploratory research study is to expand the current understanding of the relationship between organizational identification and learning organization dimensions in the context of a franchise network.

The learning organization contains a people and structure orientation in support of the organizational learning process (Song, Joo, \& Chermack, 2009). Under these conditions, the learning organization is a system that learns in successively more complex levels through social interactions, toward clear goals (Marquardt, 2002; Watkins \& Marsick, 1993).

Michael Marquardt wrote, "globalization and technology have forced companies to transform themselves significantly in order to survive in a new world and its new economy" (2011, p. vii). Marquardt points to learning as the solution. "Organizations must learn even faster and adapt more seamlessly to changes in the environment or they simply will not survive" (2011, p. vii). Watkins and Marsick (1993) pointed to learning as a social process whereby learning progresses "at successively complex, collective learning levels in organizations: individuals, groups and 
teams, larger business units and networks, the organization itself, its network of customers and suppliers, and other societal groups" (p. 9). Marsick and Watikins (1993) relate learning as a system process that begins at the individual interaction.

Watkins and Marsick (1993) pointed to three main reasons why we need organizational learning: "changes in organizations, changing nature of work, and changes in the workplace and in how people learn" (p. 5). If an organization is to compete, good foundations in structures presented in a learning organization may prove to be important keys to success. Marsick and Watkins (2003) stated that "there should be little doubt that a culture oriented toward supporting learning can lead to improved performance” (p. 142). Previous empirical studies of learning organizations have shed light on the positive impacts a learning culture create on organizational performance (Ellinger, Ellinger, Yang, \& Howton, 2002; Marsick \& Watkins, 2003). Studies have also shown the impact of the learning organization on motivation to transfer learning and job satisfaction (Dirani, 2009; Egan, Yang, \& Bartlett, 2004).

If the benefits of learning organization dimensions are promoted through social interactions as described by Watkins and Marsick (1993), an intertwined relationship with other organizational theories may exist to promote learning or be promoted by learning. As one example, organization identification also occurs in a social context as an individual in the organization attempts to understand his or her relationship to the collective group.

Organization identification includes both the cognitive and affective elements in defining the linkage between the organization and the individual. Edwards (2005) provided a useful organizational identification definition in his description of "a psychological linkage between the individual and the organization whereby the individual feels a deep, self-defining affective and cognitive bond with the organization as a social entity" (p. 227). This linkage between the individual and the collective is the basis of organizational identification. Or, as Ashforth \& Mael (1989) described the phenomena, organizational identification is the creation of oneness with an organization.

Positive consequences of organizational identification have appeared throughout the literature. Benefits congregate in two interrelated clusters. The first cluster contains the benefits to the employee and the second, more prevalent cluster, defines the benefits to the organization. Employee benefits generally highlight social classification, demand coping, behavior classification, decision making, sense-making, psychological attachment, emotional ties, self-worth, and feelings of belonging (Asforth \& Mael, 1989; Barker, 1993; Barker \& Tompkins, 1994; Cheney, 1983; Dutton, J., Dukerich, J., \& Harquail, C, 1994; Pratt, 2000). Organization benefits tend to align with the outcomes resulting from the aforementioned employee benefits. In general, the arguments contend that employees who identify with the group tend to better enact organizational interests in work-related decisions, agree more with organizational goals and objectives, and possess stronger motivational ties that result in increased output (Asforth \& Mael, 1989; Barker \& Tompkins, 1994; Cheney, 1983; Dutton et al., 1994; Pratt, 2000). Organizational identification manifests as reduced turn-over, improved job satisfaction, increased organizational citizenship behavior, increased cooperation and participation, improved effort, aligned cognitive decision making, and possible employee control (Barker \& Tompkins, 1994; Dukerich, Golden, \& Shortell, 2002; Edwards, 2005; Mael \& Ashforth, 1992).

Learning organization dimensions may be one such organizational theory related to organizational identification. The two concepts may interact and result in symbiotic improvement to the organizational entity. However, there is limited empirical exploration of a relationship between organizational identification and learning organization dimensions in the literature.

The relationship between organizational identification and learning organization dimensions are important because a learning organization in an organizational context without a strong social bond component is of less benefit to the group, which limits the organizations ability to learn and adapt to the changing global environment. What would be the value to an organization of having strong dimensions of learning if no one within the organization has strong organizational identification or interest in belonging to the group? One challenging context to test the correlation between organizational identification and learning organization dimensions is that of the franchise.

\subsection{Explore Importance of the Problem}

In a September 2010 news release, the United States Census Bureau reported that franchise businesses accounted for nearly \$1.3 trillion in annual sales revenue during 2007. The 2011 Franchised Business Economic Outlook prepared by PricewaterhouseCooper for the International Franchise Association's Educational Foundation predicts continued United States franchise growth through 2011 with job growth of 2.5 percent. The 2011 Franchise Business Economic Outlook also points to United States franchise establishments increasing from 765,723 to 784,802. These figures illustrate that franchise business is big business and franchise businesses are poised for continual growth within the 
United States.

The business format agreement between the separate business entities creates a relationship complexity that Norton (1988) described as maintaining both a firm-like quality of a hierarchical organization and a market-like quality of trade separation. The firm-like quality as described by Norton (1988) "often resembles full vertical integration” (p. 199), whereas the market-like qualities "arise from the existence of trade between two entities" (p. 198).

The franchise business relationship consisting of the firm-like and market-like paradox is an interesting relationship that may challenge traditional theories of organizational identification and learning organization. This relationship complexity between separate organizations operating as one network creates a context not traditionally analyzed under learning organization theories or organizational identification. By analyzing the franchise through these theories, we may learn more about the relationship between the individual's perception of the learning organization and that individual's perception of organizational identification. Ultimately, research in this area may lead to improved methods of managing a complex and valuable business relationship.

\subsection{Describe Relevant Scholarship}

\subsubsection{Organizational Identification}

Theorist have described organizational identification as inclusive of both the cognitive and affective elements in defining the linkage between the organization and the individual. Edwards (2005) defined organizational identification as "a psychological linkage between the individual and the organization whereby the individual feels a deep, self-defining affective and cognitive bond with the organization as a social entity" (p. 227). Pratt (1998) described two paths to identification as "recognition of an organization deemed similar to one's self, or through changes in one's self to become more similar to an organization" (p. 173). These paths result from the identification process. Edwards and Peccei (2007) conceptualized organizational identification as being comprised of three subcomponent constructs: (1) categorization of the self and self-labelling, (2) integration of organization goals and values, and (3) sense of organizational belonging and membership.

- Self-categorization and labeling links to social identity theory and the reciprocal impact of the organization on the individual and the individual on the organization in the creation of identification. The self-labeling component aligns with Pratt's (1998) self-defining method whereby the individual emulates the group and adapts to fit. This component aligns with cognitive aspects of identification theory and attempts to understand how an individual categorizes him or herself with the organization. The aim of self and self-labeling is to understand if the strength of the individual's sense of self aligns with his or her perception of the organization (Edwards \& Peccei, 2007).

- Sharing of organizational goals and values draws upon cognitive aspects of identification. The sharing of organizational goals and values also aligns with the communication theorist in the integration of goals and values with the individual. This subcomponent evaluates what Pratt (1998) describes as self-referential, where one recognizes a collective similar to one's self. The aim of sharing organizational goals and values is to understand if the individual identifies with those items proclaimed by the organization.

- Sense of organizational belonging and membership is affective attachment. Similar to prior identification descriptions, this component focuses on sense of belonging, attachment, and membership with the organization. However, Edwards and Peccei (2007) warned against the attachment component being inclusive of "individual's evaluative reactions to the organization, such as pride. Nor does it include intentions to act or actual behaviors, such as intention to stay or putting oneself out on behalf of the organization" (p. 32). The removal of reference to evaluation of reactions and intentions further separates Edwards and Peccei's conceptualization from organizational commitment theories.

Prior studies of organizational identification uncovered that an individual's identification with the organization creates a benefit for both the organization and the individual (Asforth \& Mael, 1989; Barker, 1993; Barker \& Tompkin, 1994; Cheney, 1983; Dukerich, et al., 2002; Dutton et al., 1994; Edwards, 2005; Pratt, 2000). Although the benefit of identification was explored previously, limited use of the theory was applied to the franchise network, which leads to an opportunity to further investigate. Meek, Davis-Sramek, Baucus, and Germain (2011) utilized the social exchange theory to study the role of collaborative communication and commitment on franchisees' propensity to leave the network. However, they concluded that "the future of franchising research is ripe with opportunity to examine the franchisor-franchisee relationship by grounding it in theoretical frameworks offered in both marketing and organizational behavior" (p. 575). 


\subsubsection{Learning Organization Dimensions}

Watkins and Marsick stated, "learning in the learning organization is highly social" and "individuals help other individuals learn" (1993, p. 9). To foster the learning process, Marsick and Watkins described seven action imperatives that cross the three levels of the learning organization.

Watkins and Marsick (2003) built their theory based on informal and incidental learning at the individual level; this informal learning, "explains how people shape their climate and culture of learning” (p. 134). Individuals determine learning by filtering triggers of learning and then, taking action. Marsick and Watkins (2003) described learning as an "interactive, interdependent process" (p. 135). The process builds from the individual to the group or teams and from the group to the organization and eventually, external of the organization. From the interactions across these levels, Marsick and Watkins built their model. Table 1 defines the seven action imperatives within Marsick and Watkin's model.

Table 1. Seven Action Imperatives of Marsick and Watkins Learning Organization Model

\begin{tabular}{ll}
\hline \multicolumn{1}{c}{ Action Imperative } & \multicolumn{1}{c}{ Definition } \\
\hline $\begin{array}{l}\text { Create continuous } \\
\text { learning opportunities } \\
\begin{array}{l}\text { Promote inquiry and } \\
\text { dialogue }\end{array}\end{array}$ & $\begin{array}{l}\text { Learning is designed into work so that people can learn on the job; } \\
\text { opportunities are provided for ongoing education and growth } \\
\text { People gain productive reasoning skills to express their views and the } \\
\text { capacity to listen and inquire into the views of others; the culture is changed } \\
\text { to support questioning, feedback and experimentation }\end{array}$ \\
$\begin{array}{l}\text { Encourage } \\
\text { collaborative and team } \\
\text { learning }\end{array}$ & $\begin{array}{l}\text { Work is designed to use groups to access different modes of thinking; } \\
\text { valued by the culture and rewarded }\end{array}$ \\
$\begin{array}{l}\text { Create systems to } \\
\text { capture and share } \\
\text { learning }\end{array}$ & $\begin{array}{l}\text { Both high- and low-technology systems to share learning are created and } \\
\text { integrated with work; access is provided; systems are maintained }\end{array}$ \\
$\begin{array}{l}\text { Empower people } \\
\text { toward a collective } \\
\text { vision }\end{array}$ & $\begin{array}{l}\text { People are involved in setting, owning, and implementing joint vision; } \\
\text { responsibility is distributed close to decision making so that people are } \\
\text { motivated to learn toward what they are held accountable to do }\end{array}$ \\
$\begin{array}{l}\text { Connect the } \\
\text { organization to its } \\
\text { environment }\end{array}$ & $\begin{array}{l}\text { People are helped to see the effect of their work on the entire enterprise; } \\
\text { people scan the environment and use information to adjust work practices; } \\
\text { the organization is linked to its communities }\end{array}$ \\
$\begin{array}{l}\text { Provide strategic } \\
\text { leadership for learning }\end{array}$ & $\begin{array}{l}\text { Leaders model, champion, and support learning; leadership uses learning } \\
\text { strategically for business results }\end{array}$ \\
\hline
\end{tabular}

Note. Adapted from "Demonstrating the Value of an Organization's Learning Culture: the Dimensions of the Learning Organization Questionnaire," by V. Marsick and K. Watkins, 2003, Advances in Developing Human Resources 5(2), pp. 132 -151.

From a learning organization perspective, the franchisor learns from the franchisee's local knowledge (Watson, A., Stanworth, J., Healeas, S., Purdy, D., \& Stanworth, C., 2005), and the franchisees learn from the franchisor's operational and business practice knowledge (Knott \& McKelvey, 1999). Studies explored the development of knowledge within the franchise network and migration of that knowledge throughout the network both among the franchisees and between a franchisee and franchisor (Darr, Argote, \& Epple, 1995; Hoy, 2008; Kalnin \& Mayer, 2004; Knot \& McKelvey, 1999; Lindblom \& Tikkanen, 2010; Sorenson \& Sorensen, 2001; Watson et al., 2005). These studies showed how information originates and flows throughout the network; however, the perception of a presence of the dimension of a learning organization across the franchise network is underexplored. It is these learning organization dimensions that Watkins and Marsick $(1993,1999)$ described as the imperatives for an organization to create learning strategically into the system. It is in new contexts of smaller and medium-sized organizations that Song, Joe, and Chermack (2009) described as the site for future learning organization research as they stated, "size of the organization could pull out practical, interesting, and worthy results" (p. 60).

\subsection{Conceptual Framework}

The conceptual framework for the study stems from the individual's perception of social interaction between himself and the collective. Both organizational identification and learning organization constructs are foundationally built 
upon an individual's perception of those within the collective. This social perception is of significant importance within the franchise context because it must overcome the market-like qualities of the relationship and guide the relationship toward a firm-like structure where the franchisee perceives organizational identification and learning dimensions within the network in which he is only contractually affiliated. Figure 1 illustrates the conceptual framework of the study.

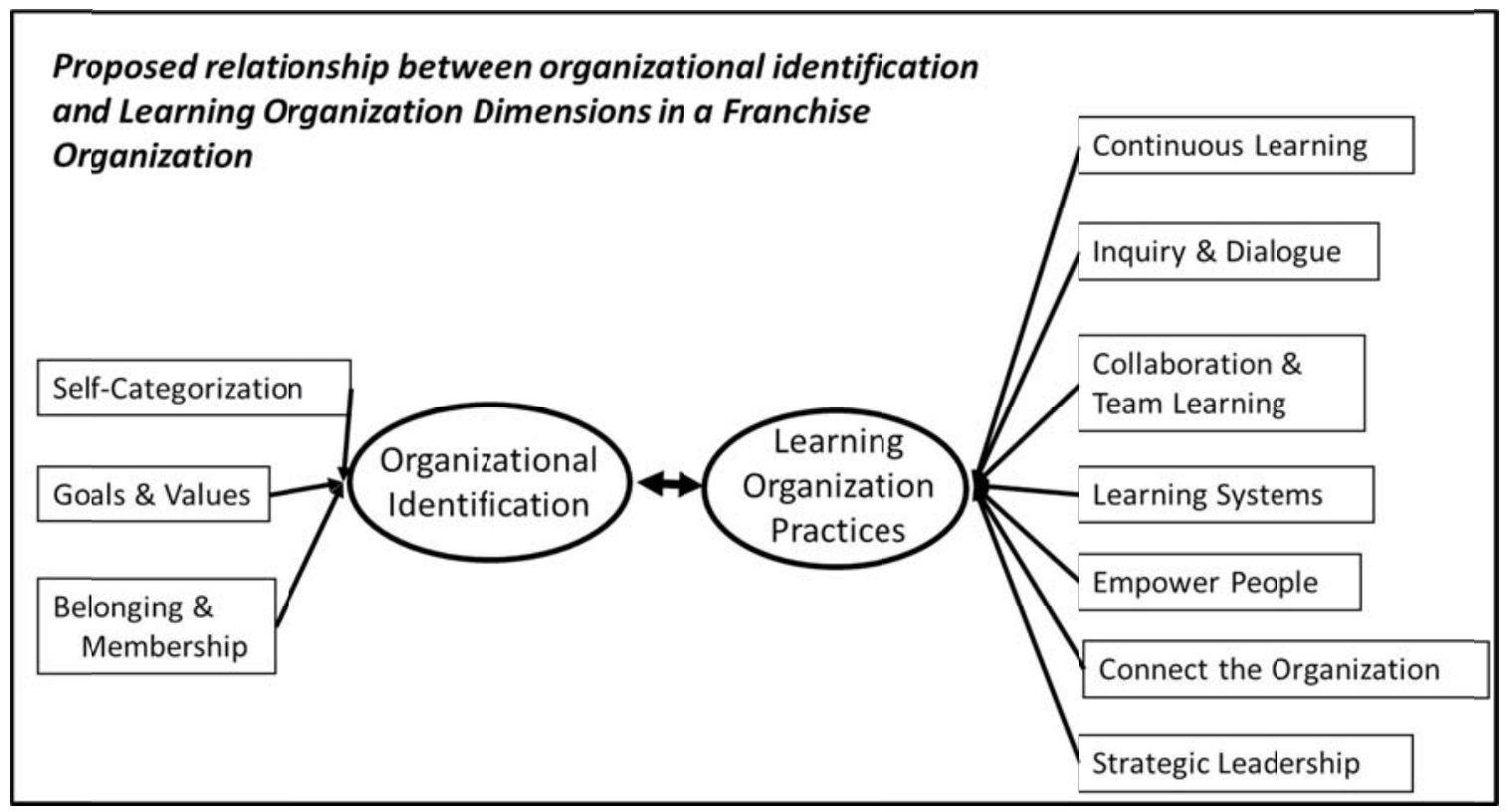

Figure 1. Conceptual Framework of the Study

\subsection{State Hypotheses and Their Correspondence to Research Design}

The purpose of this exploratory research study was to expand the current understanding of the relationship between organizational identification and learning organization dimensions as expected by the social interaction foundation present in both theories and to expand research into the franchise context.

The research questions in the study are as follows:

RQ1: To what extent is there a relationship between the franchise owner's perceptions of organizational identification with the franchise network and that franchise owner's perceptions of the learning dimensions of the franchise network?

RQ2: To what extent is there a relationship between the franchise owner's perceptions of organizational identification with the franchise network and that franchise owner's perceptions of the subscales of the learning dimensions of the franchise network?

Drawing from the research questions, the following hypotheses were designed

H1: There is a positive relationship between Organizational Identification scores and Dimensions of a Learning Organization Scores

H1a: There is a positive relationship between Organizational Identification scores and Continuous Learning scores

H1b: There is a positive relationship between Organizational Identification scores and Inquiry and Dialogue scores

H1c: There is a positive relationship between Organizational Identification scores and Collaboration and Team Learning scores

H1d: There is a positive relationship between Organizational Identification scores and Learning Systems scores

H1e: There is a positive relationship between Organizational Identification scores and Empowering People scores

H1: There is a positive relationship between Organizational Identification scores and Connect the Organization scores

H1g: There is a positive relationship between Organizational Identification scores and Strategic Leadership scores 
To investigate the relationship, the study design used Edwards and Peccei's (2007) organizational identification instrument and Marsick and Watkins' (2003) DLOQ. Organizational identification was measured at the aggregate level and dimensions of the learning organization were measured down to the action imperatives. The unit of analysis for this study was the individual. Each individual completed a survey instrument using his or her perception of organizational identification and dimensions of the learning organization.

\section{Method}

\subsection{Participants}

The study was conducted with one franchisor's network operating in the United States. The selected franchisor network contained 81 franchisee owners operating over 200 franchise units across the United States. The organization was founded in 1991 and franchising of local markets began in 1994. Therefore, from a franchise age perspective, the network was mature enough to have overcome the initial stages of development, yet young enough to have franchisees in early stages of development.

The specific franchise was selected for four key reasons. First, the franchise was a medium-sized, U.S.-based operation. The size is important in this case because with 81 owners and one corporate contact at the franchise headquarters, the message would be more consistent than a study of a much larger organization. Also, since only the U.S. franchisees were studied and the franchise development director was in place since 2004, there was less chance of inconsistent message or improper message interpretation.

Second, the franchise was also selected because it possessed a relatively small structure at the franchisee level with relatively low turnover. Each franchisee had a small, select group of employees that infrequently departed the organization. The franchisee owner often also acted as the operator. With the franchisee owner actively involved in the organization, he or she acted as the liaison between the franchisor and the highly skilled workforce. Therefore, the franchisee owner's perceptions of the franchise network were considered instrumental in the organization's success.

Third, the franchise's high regard for ever-changing knowledge was another key selection criterion. As the corporate website states, only one of ten job applicants are able to meet the rigorous standards of hands-on training. Also, the website states that the job tasks performed by the employees are ever-changing and increasingly more complex. To survive and remain at the top of this industry, which this franchise network had done since inception, the franchise prides itself on a strong knowledge structure. To illustrate this pride, when describing itself on the corporate website, the franchise provides (a) our state-of-the-art training facilities, and (b) technicians trained in the latest technology as the top two reasons for what made them stand out from competitors. As the website professes, "all technicians remain up-to-date on the latest technology and use the latest and most effective tools to ensure that you receive the best service possible". To remain up-to-date in an ever-changing environment, the franchisor is "closely allied with the leading researchers in technology, ensuring that they have the latest and most effective tools for programming".

The final selection criterion was the franchise's continual success. On external measures, it remained the top of its category in rankings by Entrepreneur Magazine and continued to improve its ranking versus all franchises improving from an overall ranking of 417 in 2008 to 131 in 2012. In addition to overall franchise ranking by Entrepreneur Magazine, in 2011 the franchise was also ranked in the top 100 of fastest-growing franchises and top 50 home-based franchises by Entrepreneur Magazine.

\subsection{Instrument}

The study used a quantitative research design and utilized a 35 item survey instrument. To investigate the relationship, the study design used Edwards and Peccei's (2007) organizational identification instrument and Marsick and Watkins' (2003) DLOQ. The organizational identification and learning organization sections of the instrument remained unchanged from previous studies, which added in relative comparison of descriptive statistics. The unit of analysis for this study was the individual franchisee owner. Each franchisee owner received a survey instrument and was asked his or her perception of organizational identification and dimensions of the learning organization.

\subsection{Procedures}

The franchise headquarters provided access to the entire franchisee owner population through contact emails and mailing address information. To maximize response rates, the survey was administered via the Internet during a two-week period in the last quarter of the year. Generally, this period was considered down time for the franchisees 
in this network and coincided with two other network-wide surveys. Use of the Internet reduced accessibility bias as it removed the ability to select participants based upon access (Alreck \& Settle, 2004).

The first communication occurred when the survey was opened and was followed by the second communication seven days after the survey opened. A final communication occurred just prior to the survey closing date. All communications were through use of the email distribution list provided by the franchisor. All participants received all communications.

Nonresponse bias was measured to ensure that those not responding to the survey were as independent of the survey content as possible (Alreck \& Settle, 2004). To ensure that the nonresponse did not impact the study, a series of qualifying demographic questions were included within the survey.

The survey was administered via SurveyMonkey. The initial question, which required response, contained consent authorization. All other questions aligned with the instruments described above or general demographic questions.

\section{Results}

\subsection{Response Rate}

Of the 81 target franchisee owners, 58 actually responded to the survey for an overall response rate of $72 \%$. Of those 58 responses, 7 were incomplete and removed from the study. The resulting 51 responses provided a survey response rate of $65 \%$.

A proportionate mix of owners of original franchise locations versus owners of existing franchise locations in addition to a consistent range of ownership tenure is useful to understand learning interactions. Tenure, for example, is important because Wang (2009) found that, at different tenured stages, local managers acted differently in gathering knowledge from network sources. Kuhn and Nelson (2002) also pointed to the importance of tenure when they used a longitudinal case study to explore how the identification process unfolds over time. Therefore, a mixture of tenure captures the impact of differing learning organization and organizational identification perceptions that may result from participants having consistent time in the network.

Of those who responded, 29 were original franchisee owner, which indicates that they started the franchise versus the other 22 who purchased a franchisee already in operation. In total, the franchisees have operated the franchise locations for varying tenures.

\subsection{Reliability}

In this study, respondents were asked to complete six items from the organizational identification instrument created by Edwards and Peccei (2007) and 21 items from the DLOQ created by Marsick and Watkins' (1993, 1997). To test the reliability of the two survey instruments, Cronbach's alpha coefficients were calculated. The Cronbach's alpha for the perception of organizational identification in this study was .938, which indicates strong reliability.

Table 2 contains the computed Cronbach's alpha for each of the seven dimensions of Marsick and Watkins DLOQ instrument and the Cronbach's alpha for the action imperatives of a learning organization. The results of the seven dimensions ranged between .634 and .896. The overall DLOQ result was .97. In all dimensions except that of connect the organization to its environment the Cronbach's alpha exceeded 0.8.

Table 2. Cronbach's Alpha for Action Imperatives of a Learning Organization

\begin{tabular}{lc}
\hline \multicolumn{1}{c}{ Imperatives } & Cronbach's Alpha \\
\hline Create continuous learning opportunities & 0.879 \\
Promote inquiry and dialogue & 0.896 \\
Encourage collaborative and team learning & 0.828 \\
Create systems to capture and share learning & 0.868 \\
Empower people toward a collective vision & 0.812 \\
Connect the organization to its environment & 0.634 \\
Provide strategic leadership for learning & 0.862 \\
\hline
\end{tabular}




\subsection{Descriptive Statistics}

Table 3 shows the results for each question of the organizational identification on a 1 to 5 scale. Table 3 indicates that all averages were high. What the organization stands for was the highest (4.24), and goals and value alignment was also high (4.16). Scores related to belonging and membership scored the lowest (4.12 and 4.02). Therefore, as indicated in Table 3 the cognitive elements of self-labeling and of values and goals scored higher than the affective elements of belonging and membership.

The total organizational identification scale mean was 4.15 and standard deviation was .845.

Table 3. Descriptive Statistics of Organizational Identification Questions in the Study

\begin{tabular}{llcc}
\hline \multicolumn{1}{c}{ Category } & \multicolumn{1}{c}{ Question } & Mean & $\begin{array}{c}\text { Std. } \\
\text { deviation }\end{array}$ \\
\hline Self-labeling & My employment with __ is a big part of who I am & 4.16 & .976 \\
& I consider myself a ___ person & 4.20 & .969 \\
Values and goals & What___ stands for is important to me & 4.24 & 1.041 \\
& I share the goals and values of ___ & 4.16 & .976 \\
Belonging and & My membership with ___ is important to me & 4.12 & .982 \\
membership & I feel strong ties with___ & 4.02 & .915 \\
\hline
\end{tabular}

Note. Questions from "Organizational identification: Development and testing of a conceptually grounded measure," by M. Edwards and R. Peccei, 2007, European Journal of Work and Organizational Psychology, 16, 1, 25 - 57.

The mean for the Learning Organization system in total across all questions was 4.37 and the standard deviation was .96. The perception of systems to capture and share learning was the lowest of the seven subscales. My organization measures the results of the time and resources spent on training scored exceptionally low, indicating that participants did not perceive the organization as measuring time and resources spent in training. Similarly, My organization creates systems to measure gaps between current and expected performance scored low, which also indicated low perception of system in place to measure performance gaps. In addition to low mean scores, these questions had very high standard deviations. Therefore, the range of responses on these questions was the greatest. Table 4 shows the mean and standard deviation for each of the seven dimension of the Learning Organization.

The dimension with the lowest score was the creation of systems to capture and share learning $(\mathrm{M}=3.92)$. This subscale also had the greatest standard deviation $(\mathrm{SD}=1.266)$. Both provide strategic leadership for learning $(\mathrm{M}=$ 4.60) and create continuous learning opportunities $(M=4.58)$ subscales were scored high by participants.

Table 4. Descriptive Statistics of Learning Organization Imperatives in the Study

\begin{tabular}{lcr}
\hline \multicolumn{1}{c}{ Imperatives } & Mean & Std. deviation \\
\hline Create continuous learning opportunities & 4.58 & 1.074 \\
Promote inquiry and dialogue & 4.29 & 1.109 \\
Encourage collaborative and team learning & 4.35 & 1.007 \\
Create systems to capture and share learning & 3.92 & 1.266 \\
Empower people toward a collective vision & 4.51 & .962 \\
Connect the organization to its environment & 4.37 & 1.007 \\
Provide strategic leadership for learning & 4.60 & 1.052 \\
\hline
\end{tabular}

\subsection{Hypothesis Testing}

\subsubsection{RQ1 and H1}

The Pearson product-moment correlation coefficient indicates that the degree of correlation between organizational identification and learning organization dimensions is .468 and significant at the 0.01 level (two-tailed). A bivariant scatterplot of organizational identification and learning organization dimension indicated a positive correlation or direction in the relationship and the shape of the scatterplot indicated that homoscedasticity was retained in the participant responses. 


\subsubsection{RQ2 and H1a - H1g}

The Pearson product-moment correlation coefficient indicates that the degree of correlation between organizational identification and the subscales of the learning organization. Table 5 outlines the correlation values for all seven dimensions. All dimensions except for Create systems to capture and share learning reflected correlations significance at the level of 0.01 (two-tailed). That dimension had the lowest correlation $r=.317$ and was significant at the level of 0.05 (two-tailed). Encouraging collaboration and team learning had the highest correlation at .551. All other dimensions ranged from .375 to .473 .

Table 5. Correlation of Organization Identification to Seven Action Imperatives of the Learning Organization

\begin{tabular}{lc}
\hline \multicolumn{1}{c}{ Dimension } & Organizational identification \\
\hline Create continuous learning opportunities & $0.375^{* *}$ \\
Promote inquiry and dialogue & $0.426^{* *}$ \\
Encourage collaborative and team learning & $0.551^{* *}$ \\
Create systems to capture and share learning & $0.317^{*}$ \\
Empower people toward a collective vision & $0.400^{* *}$ \\
Connect the organization to its environment & $0.426^{* *}$ \\
Provide strategic leadership for learning & $0.473^{* *}$ \\
\hline
\end{tabular}

${ }^{*} p<0.05$

${ }^{* *} p<0.01$

\section{Discussion}

\subsection{Descriptive Statistics Discussion}

The strength of organization identification in the franchise of this study was stronger than previous studies using Edwards and Peccei's organizational identification instrument. As a relative comparison, Table 6 contains the mean and standard deviation values from Edwards and Peccei's (2007) previous use of the instrument. Notice that in all cases the scores in this study exceeded the results from Edwards and Peccei (2007). The differences in the business context of these studies may account for the differences in results. However, the stronger organization identification results in a franchise context were unexpected because of the business format complexities described by Norton (1988).

Table 6. Organization Identification Descriptive Statistics

\begin{tabular}{|c|c|c|c|c|}
\hline \multirow[b]{2}{*}{ Dimension } & \multicolumn{2}{|c|}{$\begin{array}{c}\text { Edwards, Peccei } \\
\text { (2007) } \\
\text { Study } 1 \\
\end{array}$} & \multicolumn{2}{|c|}{$\begin{array}{c}\text { Edwards, Peccei } \\
\text { (2007) } \\
\text { Study } 1 \\
\end{array}$} \\
\hline & Mean & $\begin{array}{c}\text { Std. } \\
\text { deviation }\end{array}$ & Mean & $\begin{array}{c}\text { Std. } \\
\text { deviation }\end{array}$ \\
\hline Self-Categorization and Labeling & 3.21 & 0.97 & 3.40 & 0.94 \\
\hline Sharing Goals and Objectives & 3.51 & 0.71 & 3.63 & 0.86 \\
\hline Belonging and Membership & 3.25 & 0.90 & 3.44 & 0.95 \\
\hline
\end{tabular}

Similarly, the strength of the dimensions of the learning organization in this study were among the highest of eight previous studies across multiple businesses. These results may illustrate that Watkins and Marsick's DLOQ has little negative impact associated with franchise business format. However, that finding again would be unexpected because the business format tensions in a franchise would lead to an expectation that the dimensions of a learning organization would be lower than fully integrated organizations.

\subsection{Hypothesis Discussion}

\subsubsection{RQ1 and H1}

The result of a moderately strong positive relationship between organizational identification and learning organization dimensions aligns with the similarities in the foundation of organizational identification and learning organization. Both develop from the social interactions between individuals and the collective. 
For organizational identification to be strong, the individual must recognize both cognitively and affectively a tie with the collective. One key aspect of this tie between the individual and the collective is goals and values (Edwards \& Peccei, 2007). As Dutton et al. (1994) described identification, "when organizational identification is strong, a member's self-concept has incorporated a large part of what he or she believes is distinctive, central, and enduring about the organization into what he or she believes is distinctive, central, and enduring about him- or herself” (p. 242). Strong organizational identification indicates a sense of alignment between the individual and the organization both at an affective and cognitive level.

As Hardy, Lawrence and Grant (2005) described, collective identity is created and consequently then translates into effective collaboration in an inter-organizational context. Their study concluded that "participants first need to produce a collective identity through the establishment of both generalized and particularized membership ties" to create collaboration (p. 73)

The correlation with learning organization occurs directly through collaboration or inquiry and dialogue. As Watkins and Marsick (1993) stated, "inquiry is a dialogue in which people mutually explore ideas, questions, and potential actions” (p. 73). Watkins and Marsick also pointed to the strength of talk and open minded inquiry to the learning organization process by illustrating how individuals make localized assumptions and groups convert individual assumptions into shared meanings. These shared meanings inform the learning process.

Underlying the organizational identification theory are the cognitive and affective elements, and, if those are strong, it follows that the individuals will actively turn to the group when confronted with a learning stimulus. The group will then interact with the individual in a reciprocal learning process. Similarly, underlying the learning organization theory is the interaction between members.

Therefore, at the foundation, both organizational identification and learning organizations occur through interactions of an individual with the collective. Identification is the bond and this correlation may indicate that the learning organization could build from that bond. Or conversely, strong dimensions of the learning organization could result in strengthening of organizational identification. In this study, the strength of organizational identification within the franchise network likely impacted the learning organization perception or vice versa or impacted by another variable not being explored, which is exactly what correlation indicates.

\subsubsection{RQ2 and H1a-H1g:}

Organizational identification was most strong and positively correlated with the subscale of encouraging collaborative and team learning. At the basis of this subscale is the concept of crossing or spanning boundaries (Watkins \& Marsick, 1993). This boundary crossing is described by Watkins and Marsick (1993) as soliciting help, collaborating with others or actively listening. They postulated that "when people cross boundaries outside of their teams, organizational learning take place" (p. 102). Watkins and Marsick described three factors that most influence team learning: (a) appreciation of teamwork, (b) promotion of inquiry and dialogue, and (c) operating principles which include support of operating teams and cross functional work.

Organizational identification has been shown to promote collaboration, so it follows that a correlation could exist between organization identification and collaboration and teamwork. But, organizational identification could go one step further. Creation of a learning organization develops the culture of learning, but does not promote or elicit involvement. Organizational identification describes the degree to which people may collaborate or be involved. Stronger organizational identification may beget greater degree of collaboration. Organizational identification may be one variable that creates the reason to collaborate and become involved in teamwork. The correlation between organizational identification and encouraging collaboration and team learning subscale is a possible future area of study that will be discussed later.

Strategic leadership for learning subscale and organizational identification were moderately strong in correlation with a correlation coefficient of .473 at a significance of .01. When looking at the concept of a franchise network, strategic leadership is very fragmented. Each franchise owner can essentially create his or her own leadership strategies and progress initiatives as desired. However, this aligns directly with Marsick and Watkin's (1999) description of leaders in the learning organization. As they stated, "leaders must provide a safe space in which people can take on new behaviors and realize that it is expected that they challenge the status quo" (p. 159). The design of a franchise network could create that exact dynamic. The franchisor simply pulls the network toward a common direction. In the case of this study, the franchisor points to a high regard for ever-changing knowledge and increasingly complex tasks of employees. These statements are described directly on the franchise website and they create a model of learning for the entire franchise network. This leadership focus on learning may explain why the 
subscale scored high.

However, one may question why the correlation exists. The correlation could exist because strong identification indicates that the franchisee network is listening to the message. They listen because they align with the values and goals of the network, which was one of Edwards and Peccei's three sub-categorizations of organizational identification. The congruence between the franchise's strategic leadership with the values and goals can be impacting the entire network, and this is a possible area of future focus.

Creation of systems to capture and share learning and organizational identification had the weakest correlation coefficient in the study with a coefficient of .317 at a significance of .05. As Watkins and Marsick (1993) observed, "Learning must be captured and collected in systems to keep what is learned in the organizational memory" (p. 15). From a franchise perspective, this learning system development is a difficult undertaking. It is here in the organizational realm of the learning organization model where strategy or vision interacts with practical tactics. These tactics or systems to capture and share are typically difficult for a franchise network. Darr et al. (1995) uncovered this complexity and the inability of knowledge transfer between franchisee owners when they viewed the impacts of regular communications, acquaintances, and meetings on one franchise owner's pizza operations. Not surprisingly, knowledge flowed between the locations under one owner, but did not flow into the franchisor or other franchisee owners at nearly the same speed. Sorenson and Sorensen (2001) also found this lack of systems when evaluating the comparison between franchise and locally owned locations in the same market. They found that "chains also monitored franchisee behavior, but less stringently and less systematically" than company-owned locations (p. 715). So, it is not surprising that the franchise network scored low on the systems to capture and share learning. The franchise business format has traditionally been weak in this action imperative.

The low score on this subscale created the low correlation with organizational identification because, although identification remained high, the tactical systems just did not exist. The absence of systems, however, should not be too surprising. When reviewing the information from previous studies using the DLOQ, these studies also had lower scores on this subscale. So, one could ascertain that maybe the franchise lack of systems is endemic of all organizations, not just franchises.

It appears that the franchise in this study performed very well in strategic areas such as connecting the organization to its environment and empowering people. The franchise also scored well at less quantifiable activities such as creating opportunities and promoting inquiry. These action imperatives align with organizational identification categories such as sharing goals and values and a sense of belonging and membership. Where the challenges arose in this study were the tactical application or establishing systems to capture and share learning. This action imperative creates a challenge for franchise networks and has little or no linkage with organizational identification.

\subsection{Recommendations for Future Research}

The most surprising outcomes of the study was that the market-like impacts of a franchise network did little to change the results; therefore, the paradox between market-like and firm-like qualities appeared to tilt toward firm-like in the specific franchise of this study. It would be interesting to further explore relationships in franchise businesses to understand more about the impact of an independent, yet bound organization.

It appears that empowerment of the franchise locations to create aligned goals and values may have created a sense of collaboration toward a common vision. This common vision may have overcame the market-like conditions. The alignment between the franchisor and franchisees could further support a sense of belonging and membership within the organization. Possible future research could explore more specifically how the correlation came into existence.

One could question if the franchise business format is really different from a corporate owned outlet. The question of differences between franchise and corporate owned was not addressed in this study. If an organization operated a hybrid structure where some local locations are company-owned and others are franchise-owned, an immediate comparison could occur.

In this case the sub elements of organizational identification such as belonging and membership and goals and objectives all seem well align. This alignment may have contributed to the learning organization structure.

There is no shortage of other variables to address as possible moderating variables. The demographic section of the survey instrument described a few such as tenure, and original ownership versus purchased ownership, and communication method between the parties. Other possibilities are limitless.

The results of this study and the investigation into descriptive statistics revealed that the DLOQ appears to continually score low in the sub element of creating systems to capture and share learning. The scores on this sub 
element lead to two possibilities, either organizations typically perform poorly in this area or the questions are difficult to interpret or associate to a learning organization. Whatever the cause, future research should explore this sub element more closely.

\subsection{Summary}

This study highlighted the relationship between the perceptions of organizational identification and the perceptions of a learning organization in a franchise network. It extended current research by exploring these concepts in the franchise network where the business relationship challenges traditional studies.

The study explored the relationship in one U.S.-based, medium-sized franchise network. The descriptive statistics showed that the franchise results were not too different from previous studies. The correlation results showed that areas where collaboration, team work, vision, and goals existed resulted in moderately strong-to-strong results. These results could stem from similar antecedents to both organizational identification and learning organization action imperatives. Those antecedents include goals, vision, membership, collaboration, and belonging.

The study calls attention to the similarities between the two theories and recommendations were created for future exploratory studies. The study begins to fill the void Meek and his colleagues (2011) described when they request for researchers to "tease out the relationship nuances, paying particular attention to relational variables that will create more insight about the potential benefits gained from stronger relationships" (p. 575). This study showed that one benefit of a stronger relationship is strong perception of a learning organization and strong organizational identification.

One of the most surprising outcomes of the study was that the market-like impacts of a franchise network did little to differentiate results from prior studies. The paradox between market-like and firm-like qualities definitely appeared to tilt toward firm-like in the specific franchise of this study.

\section{References}

2012 Franchise 500 Ranking. (2012). Entrepreneur.com. Retrieved January 6, 2013, from http://www.entrepreneur.com/franchises/rankings/franchise500-115608/2012,-1.html

Alreck, P., \& Settle, R. (2004). The survey research handbook ( ${ }^{\text {rd }}$ ed.). Boston: McGraw-Hill Irwin.

Ashforth, B., \& Mael, F. (1989). Social identity theory and the organization. Academy of Management Review, 14(1) $20-39$.

Baker, J. (1993). Tightening the iron cage: Concertive control in self-managing teams. Administrative Science Quarterly, 38, 408-437. http://dx.doi.org/10.2307/2393374

Barker, J., \& Tompkin, P.K. (1994). Indentification in the self-managing organization. Human Communication Research, 21(2), 223-240. http://dx.doi.org/10.1111/j.1468-2958.1994.tb00346.x

Cheney, G. (1983). On the various and changing meanings of organizational membership: A field study of organizational identification. Communication $\quad$ Monographs, 50, 342-362. http://dx.doi.org/10.1080/03637758309390174

Darr, E., Argote, L., \& Epple, D. (1995). The acquisition, transfer, and depreciation of knowledge in service organizations: Productivity in franchises. Management Science, 41(11), 1750-1762. http://dx.doi.org/10.1287/mnsc.41.11.1750

Dirani, K. (2009). Measuring the learning organization culture, organizational commitment and job satisfaction in the Lebanese banking sector. Human Resourve Development International, 12(2), 189-208. http://dx.doi.org/10.1080/13678860902764118

Dukerich, J., Golden, B., \& Shortell, S. (2002). Beauty is in the eye of the beholder. Administrative Science Quarterly, 47(3), 507-533. http://dx.doi.org/10.2307/3094849

Dutton, J., Dukerich, J., \& Harquail, C. (1994). Organizational images and member identification. Administrative Science Quarterly, 39, 239-263. http://dx.doi.org/10.2307/2393235

Edwards, M. (2005). Organizational identification: A conceptual and operational review. International Journal of Management Reviews, 7(4), 207-230. http://dx.doi.org/10.1111/j.1468-2370.2005.00114.x

Edwards, M., \& Peccei, R. (2007). Organizational identification: Development and testing of a conceptually grounded measure. European Journal of Work and Organizational Psychology, 16(1), 25-57. 
http://dx.doi.org/10.1080/13594320601088195

Egan, T., Yang, B., \& Bartlett, K. (2004). The effects of organizational learning culture and job satisfaction on motivation to transfer learning and turnover intention. Human Resource Development Quarterly, 15(3), $279-301$. http://dx.doi.org/10.1002/hrdq.1104

Ellinger, A., Ellinger, A., Yang, B., \& Howton, S. (2002). The relationship between the learning organization concept and firms' financial performance: An empirical assessment. Human Resource Development Quarterly, 13(1), 5-21. http://dx.doi.org/10.1002/hrdq.1010

Hardy, C., Lawrence, T., \& Grant, D. (2005). Discourse and collaboration: The role of conversation and collective identity. Academy of Management Review, 30(1), 58-77. http://dx.doi.org/10.5465/AMR.2005.15281426

Harrison, A., \& Haller, M. (2011). 2011 Franchise business economic outlook. [MicroSoft Word Document]. Retrieved from http://www.franchise.org/Franchise-News-Detail.aspx?id=52727

Hoy, F. (2008). Organizational learning at the marketing/entrepreneurship interface. Journal of Small Business Management, 46(1), 152-158. http://dx.doi.org/10.1111/j.1540-627X.2007.00237.x

Kalnins, A., \& Mayer, K. (2004). Franchising, ownership, and experience: A study of pizza restaurant survival. Management Science, 50(12), 1716-1728. http://dx.doi.org/10.1287/mnsc.1040.0220

Knott, A., \& McKelvey, B. (1999). Nirvana efficiency: A comparative test of residual claims and routines. Journal of Economic Behavior \& Organization, 38, 365-383. http://dx.doi.org/10.1016/S0167-2681(99)00016-5

Kuhn, T., \& Nelson, N. (2002). Reengineering identity: A case study of multiplicity and duality in organizational identification. Management Communication $\quad$ Quarterly, $16(1), \quad$ 5-38. http://dx.doi.org/10.1177/0893318902161001

Lindblom, A., \& Tikkanen, H. (2010). Knowledge creation and business format franchising. Management Decision, 48(2), 179-188. http://dx.doi.org/10.1108/00251741011022563

Mael, F. A., \& Ashforth, B. E. (1992). Alumni and their alma matter: A partial test of the reformulated model of organizational identification. Journal of Organizational Behavior, 13, 103-123. http://dx.doi.org/10.1002/job.4030130202

Marquardt, M. (2002). Building the learning organization (2nd ed.). Palo Alto, CA: Davies-Black Publishing, Inc.

Marquardt, M. (2011). Building the learning organization (3rd ed.). Palo Alto, CA: Davies-Black Publishing, Inc.

Marsick, V., \& Watkins, K. (1994). The learning organization: An integrative vision of the HRD. Human Resource Development Quarterly, 5(4), 353-360. http://dx.doi.org/10.1002/hrdq.3920050406

Marsick, V., \& Watkins, K. (2003). Demonstrating the value of an organization's learning culture: The dimensions of the learning organization questionnaire. Advances in Developing Human Resources, 5(2), 132-151. http://dx.doi.org/10.1177/1523422303005002002

Meek, W.R., Davis-Sramek, B., Baucus, M., \& Germain, R.N. (2011). Commitment in franchising: The role of collaborative communication and a franchisee's propensity to leave. Entrepreneurship Theory and Practice, 35, 559-581. http://dx.doi.org/10.1111/j.1540-6520.2011.00445.x

Norton, S. (1988). An empirical look at franchising as an organizational form. Journal of Business, 61(2), 197-218. http://dx.doi.org/10.1086/296428

Pratt, M. (1998). To be or not to be? central questions in organizational identification. In Whetten, D. \& Godfrey, P. (p. 171-207). Thousand Oaks, CA: Sage Publications.

Pratt, M. (2000). The Good, The bad and the ambivalent: Managing identification among Amway distributors. Administrative Science Quarterly, 45, 456-493. http://dx.doi.org/10.2307/2667106

Song, J., Joo, B., \& Chermack, T. (2009). The dimensions of learning organization questionnaire (DLOQ): A validation study in a Korean context. Human Resource Development Quarterly, 20(1), 43-64. http://dx.doi.org/10.1002/hrdq.20007

Sorenson, O., \& Sorensen, J. (2001). Finding the right mix: Franchising, organizational learning, and chain performance. Strategic Management Journal, 22, 713-724. http://dx.doi.org/10.1002/smj.185

Wang, C., \& Altinay, L. (2008). International franchise partner selection and chain performance through the lens of organizational learning. The Service Industries Journal, 28(2), 225-238. 
http://dx.doi.org/10.1080/02642060701842290

Wang, F. (2009). Identification of MNC knowledge resources for the local market: An examination of 7-Eleven's international licensing operations. The International Review of Retail, Distribution, and Consumer Research, 19(5), 535-551. http://dx.doi.org/10.1080/09593960903445418

Watkins, K., \& Marsick, V (1993). Sculpting the learning organization. San Francisco, CA: Jossey-Bass Publishers.

Watson, A., Stanworth, J., Healeas, S., Purdy, D., \& Stanworth, C. (2005). Retail franchising: An intellectual capital perspective. Journal of Retailing and Consumer Services, 12, 25-34. http://dx.doi.org/10.1016/j.jretconser.2004.02.001 